\title{
Modificación a la ley de partidos políticos: más (y mejor) de los mismo... pero sigue siendo lo mismo
}

\author{
Changes to the law on political parties: \\ more (and better) of the same...but still the same \\ JUAN PABLO BECA FREI ${ }^{1}$ \\ Universidad Católica de Temuco, Chile
}

RECEPCIÓN: 25/09/2017 • ACEPTACIÓN: 27/11/207

RESUMEN: Desde que está vigente la Ley Orgánica Constitucional de Partidos Políticos esta ha sufrido varias modificaciones, pero solo las últimas son de carácter sustantivo, las que siguen los lineamientos de la Comisión Engel y buscan democratizar la estructura de los partidos, acercarlos a la ciudadanía y mejorar así la calidad de la democracia.

Se cambia la naturaleza jurídica de los partidos (que pasan de tener personalidad jurídica de derecho a privado a una de derecho público); se introducen algunas modificaciones en sus funciones y se muda el carácter del mandato de los parlamentarios, dando más relevancia a los partidos. Junto con ello se les concede a los mismos un financiamiento estatal de carácter permanente, pero como contrapartida, se observa un mayor nivel de intervención estatal en sus aspectos internos.

Todo ello, sin embargo, no recoge nuevas tendencias y cuestionamientos a las estructuras y concepciones tradicionales. Los partidos siguen siendo considerados como ideológicos, de masas, y siguen siendo mirados con desconfianza. Si bien se mejora la regulación, no se cambia el paradigma con que se construyó la ley durante la dictadura.

1. Magíster en Derecho. Profesor de la Facultad de Ciencias Jurídicas de la Universidad Católica de Temuco. email: jbeca@uct.cl 
PALABRAS CLAVE: Partidos Políticos - Democracia - Financiamiento - Estructura

ABSTRACT: Since the Organic Constitutional Law on Political Parties came in to effect, it has under gone several changes; however, only the last two can be considered essential. These follow the proposals of the Engel Commission, and seek to democratize parties' structure, bringing them closer to citizens and thus improving the quality of democracy.

The legal nature of political parties has been changed, since they are granted a public legal personality instead the private personality that they used to have; some changes in their role have been introduced, and the kind of mandate that the members of parliament have is also reformed, increasing parties' relevance. Further more, parties are granted permanent public funding, although under the condition of accepting increased state intervention in their internal affairs.

Nevertheless, the new regulations do not consider new tendencies and the current questioning of traditional structures and conceptions. Political parties are still considered to be ideological mass organizations, and are still viewed with mistrust. Although regulation is improved by the changes, the paradigm underlying the law passed by the dictatorship has not changed.

KEYWORDS: Political Parties - Democracy - Financing - Structure.

\section{Introducción}

A lo largo del trabajo revisaremos las opiniones vertidas durante la tramitación parlamentaria de las modificaciones a la ley de partidos políticos, contrastándola con algunos elementos de la realidad actual, así como con opiniones de doctrina.

Se podrá advertir que si bien existió la intención de mejorar el sistema de partidos, con miras a avanzar en el propio sistema democrático de gobierno, fruto de los fuertes niveles de desconfianza, los cambios introducidos no guardan relación con las necesidades actuales del sistema político, por lo que no es esperable que surtan el efecto buscado.

\section{Aspectos generales}

La Ley Orgánica Constitucional de Partidos Políticos (Ley No 18.603) fue dictada en 1987, junto con otras leyes de carácter político, hacia el final de la dictadura que 
se instaló en Chile a partir de 1973, para preparar normativamente el plebiscito que contemplaba la disposición vigesimoséptima transitoria del texto original de la Constitución Política de la República, en el cual se rechazó la propuesta de los Comandantes en Jefe de las Fuerzas Armadas y del General Director de Carabineros en orden a que el General Augusto Pinochet ejerciera la Presidencia de la República en el período comprendido entre 1989 y 1997. Como se comprenderá, este contexto es radicalmente distinto del que existe actualmente, trascurridos veintiocho años desde la instalación del primer gobierno democráticamente elegido después de la mencionada dictadura. La ley es "fruto de su época" ${ }^{2}$, pero ello no puede entenderse referido solo al contexto de dictadura; también debemos considerar una conformación y comprensión distinta de la representación ciudadana, es ese entonces más centrada en ideologías, con una concepción de las organizaciones partidarias como partidos de masas y fuertemente ideológicos, lo que no se condice con la realidad actual ${ }^{3}$. Actualmente los vínculos son más bien no programáticos o clientelares, caracterizados por "transacción de información, recursos materiales, e influencia a cambio de votos" ${ }^{4}$. La ley no considera formas más líquidas de participación, como movimientos coyunturales que responden a problemáticas o intereses transitorios.

Con posterioridad, la mencionada Ley Orgánica Constitucional ha sido modificada en diversas oportunidades, pero básicamente para adecuarla a otros cambios, tales como la entrada en vigencia de la reforma procesal penal; el cambio de sistema de inscripciones electorales, que pasó de ser voluntario a ser automático, y el cambio del sistema electoral, que pasó a ser de carácter proporcional.

Recién en el año 2016 se promulgan dos leyes con cambios sustantivos a la Ley $\mathrm{N}^{0} 18.603$, estas son las leyes $\mathrm{N}^{\circ} 20.900$ y No 20.915, ambas promulgadas el día 11 de abril. La primera de ellas denominada "Para el fortalecimiento y transparencia de la democracia" y la segunda "Fortalece el carácter público y democrático de los partidos políticos y facilita su democratización”. Ambas leyes se comprenden dentro del esfuerzo por modernizar la democracia después del informe de la Comisión Engel $^{5}$, y de la necesidad de hacer frente al complejo momento que viven los partidos políticos, no solo en nuestro país, siendo "necesario dotarlos de un

2. Biblioteca del Congreso Nacional (2016), p. 6.

3. LunA (2017).

4. De Cea y Fuentes (2016)

5. Consejo Asesor Presidencial contra los Conflictos de Interés, el Tráfico de Influencias y LA Corrupción (2015). 
marco normativo acorde a los tiempos que vivimos, fortaleciendo la democracia interna de estos y sus roles en una democracia madura" ${ }^{6}$, junto con establecer el deber que estos tienen de "contribuir al fortalecimiento de la democracia y al respecto, garantía y promoción de los derechos humanos"7.

Estas últimas modificaciones, si bien se hacen cargo de algunas de las recomendaciones de la mencionada comisión, y amplía en algo el restrictivo marco legal de las actividades propias de los partidos ${ }^{8}$, están lejos de cambiar el paradigma en torno al cual se concibió la legislación que regula a los partidos políticos; si bien se introducen mejoras, no se aborda el fondo del problema ${ }^{9}$. Se legisla, en palabras de un diputado "para que todo quede exactamente igual" ${ }^{10}$. Se observa un excesivo celo de los parlamentarios, a lo largo de la tramitación del proyecto de ley, por regular de forma tal que haga posible mantener muchas de las lógicas y formas de funcionamiento de los partidos tradicionales, llegando a "acomodar la realidad de la ley en proyecto a la de los partidos existentes"11.

Se intenta enfrentar por un lado una crisis y un profundo cuestionamiento al sistema de partidos $^{12}$, y por otra la paradoja que representa el desgaste y fragilidad de los partidos frente a un marco de un sistema de partidos, presente en Chile desde el siglo XIX, fuertemente institucionalizado en torno a tipologías clásicas. Se parte del convencimiento de que "no se conoce otra forma de organización política en democracia que sea más eficaz que la representación vía partidos políticos” ${ }^{13}$, siendo "el primer eslabón de una democracia participativa" ${ }^{14}$. Se advierte también durante la discusión parlamentaria que "la ley de partidos ha contribuido a mantener un sistema de partidos relativamente congelado en el clivaje político de la transición" 15 , en parte debido al sistema binominal.

\footnotetext{
6. Biblioteca del Congreso Nacional (2016), p. 6.

7. Biblioteca del Congreso Nacional (2016), p. 309.

8. Biblioteca del Congreso Nacional (2016), p. 262.

9. Biblioteca del Congreso Nacional (2016), p. 257.

10. Biblioteca del Congreso Nacional (2016), p. 240.

11. Biblioteca del Congreso Nacional (2016), p. 601.

12. Biblioteca del Congreso Nacional (2016), p. 250.

13. Biblioteca del Congreso Nacional (2016), p. 59.

14. Biblioteca del Congreso Nacional (2016), p. 133.

15. Biblioteca del Congreso Nacional (2016), p. 62.
} 
Hay sin duda un problema de desconfianza hacia los partidos políticos ${ }^{16}$, fenómeno que no se circunscribe a nuestro país, a lo que se agregan los problemas de representatividad. Aún cuando sean estos males universales, no podemos pasar por alto que la caída en los niveles de confianza en Chile "es de las más graves de América Latina" ${ }^{17}$. Sin embargo, a los partidos se les sigue mirando con desconfianza ${ }^{18}$, no se cree en ellos ${ }^{19}$, e incluso se reconoce que se legisla a partir de prejui$\operatorname{cios}^{20}$; lo que parece contradecir la proclamada importancia que estos tienen para el funcionamiento del sistema democrático basado en instituciones ${ }^{21}$. Se mantiene una concepción de los partidos, más bien propia del siglo pasado, como partidos de masas, que no corresponde a la actual realidad de la participación ciudadana en nuestro país, lo que se pudo advertir al observar las no pocas dificultades que tuvieron los partidos tradicionales para poder reinscribirse como se les exigió, en circunstancias que para ello debían obtener un número de firmas sustancialmente menor al requerido para inscribirse por primera vez, proceso que en general les resultó más fácil ${ }^{22}$.

Se mantiene la concepción de partidos ideológicos ${ }^{23}$, sin hacerse cargo del fenómeno de "militancias temáticas, donde no se formula un principio necesariamente ideológico o político, sino más bien se adscribe a ciertas causas más que a determinadas visiones rígidas de la sociedad" 24 . No se considera lo poco atractiva que resulta la militancia tradicional para jóvenes celosos de su autonomía e independencia, quienes "quieren participar de lo público pero sin renunciar a su propio punto de vista" 25 . Por otro lado, tampoco se tiene en consideración la ingobernabilidad que podría producirse "por la gran cantidad de movimientos sociales que no

16. Programa de Naciones Unidas para el Desarrollo (2014), p. 35.

17 Biblioteca del Congreso Nacional (2016), p. 64.

18. Biblioteca del Congreso Nacional (2016), p. 551.

19. Biblioteca del Congreso Nacional (2016), p. 252.

20. Biblioteca del Congreso Nacional (2016), p. 77.

21. Biblioteca del Congreso Nacional (2016), pp. 3, 252, 262 y 543.

22. El número de firmas para inscribir partidos políticos fue, hasta el año 2015, el equivalente al $0,5 \%$ de quienes hubieren sufragado en la última elección de Diputados, siendo actualmente equivalente a $0,25 \%$ de ellos por regla general.

23. Biblioteca del Congreso Nacional (2016), p. 545.

24. Biblioteca del Congreso Nacional (2016), p. 315.

25. Biblioteca del Congreso Nacional (2016), p. 403. 
encontrará la forma de canalizarse políticamente" ${ }^{26}$. En definitiva, no se asume el desafío de hacerse cargo de cambios sociales y culturales ${ }^{27}$, y no solo de los cambios políticos que caracterizan la época en que vivimos.

\section{Naturaleza de los Partidos y su función}

Si bien no se puede advertir un cambio de paradigma en la regulación de los partidos, sí hay un cambio en su naturaleza jurídica ${ }^{28}$, al recuperar, siguiendo la tendencia comparada $^{29}$, la personalidad jurídica de derecho público de la cual gozaron en Chile entre 1971 y 1973. El Tribunal Constitucional, el ejercer el control preventivo, estimó que este aspecto es "un asunto propio del ámbito del legislador" ${ }^{30}$, dado que la Constitución no se refiere a la materia. Sin embargo, no por ello debemos considerar que este sea un aspecto de menor relevancia.

El conferir personalidad jurídica de derecho público a los partidos políticos fue resistido por un sector de los parlamentarios, manifestando temor por un eventual control estatal de los mismos ${ }^{31}$; y fue reconocido como un debate de fondo, reflejo de "la concepción que se tendrá sobre los partidos en un estado democrático" 32 . Existen entonces dos visiones radicalmente distintas, no ya del tipo de personalidad jurídica de la que deben gozar, sino sobre el rol que los partidos políticos deben cumplir para el funcionamiento del sistema democrático. Probablemente el intento por hacer convivir ambas visiones terminó por sepultar cualquier posibilidad de un real cambio de paradigma.

Se colige del contenido de la ley que hay un cambio también en la naturaleza del mandato de los parlamentarios. La eliminación de la prohibición de órdenes de partido a estos representantes, importa reconocer que son los partidos, y no los parlamentarios en forma individual, los llamados a representar a la ciudadanía, pudiendo considerarse por ello que el mandato tendrá un carácter programático.

26. Biblioteca del Congreso Nacional (2016), p. 424.

27. Biblioteca del Congreso Nacional (2016), p. 491.

28. Biblioteca del Congreso Nacional (2016), p. 260.

29. Biblioteca del Congreso Nacional (2016), p. 64.

30. Control preventivo de Proyecto de Ley, aprobado por el Congreso Nacional, que fortalece el carácter público y democrático de los partidos políticos y facilita su democratización (2016).

31. Biblioteca del Congreso Nacional (2016), p. 56.

32. Biblioteca del Congreso Nacional (2016), p. 82. 
Son los partidos políticos los que dan sustento a la actividad parlamentaria ${ }^{33}$. Un argumento para mantener la proscripción de las órdenes de partido fue precisamente el que no se podría obligar a votar de determinada manera a quien representa a la ciudadanía ${ }^{34}$, y por ello sostenemos que al rechazarse esa postura, se optó por entender que la representación ciudadana la tienen precisamente los partidos.

Este aspecto generó no poca controversia durante la discusión parlamentaria, como la genera también en la experiencia comparada ${ }^{35}$, cruzada sin duda por la visión sobre el rol de los partidos. El deber de un militante que ejerce un cargo de elección popular de votar conforme a los lineamientos partidarios, para algunos es una cuestión ética, propia de la convivencia partidaria, pues "no se puede pautear a quien ejerce soberanía popular" ${ }^{36}$; no siendo por ello un aspecto que deba ser regulado por ley, y debiendo quedar a criterio de los propios partidos, los que podrían incluso expulsar de sus filas ${ }^{37}$ a quien ya no comulga con las ideas partidarias, pero ello en nada incidiría en su calidad de parlamentario. Por otro lado se expresó también una preocupación por el "libre albedrío y racionalidad que deben sustentar los parlamentarios a la hora de votar un determinado artículo o proyecto de ley" 38 , lo que trae a la memoria el origen de los partidos políticos como agrupaciones de parlamentarios con ideas afines. Estas opiniones son reflejo de una concepción de los partidos políticos como entes privados y del mandato como eminentemente personal.

En definitiva, la pregunta crucial sería quién representa al elector, si es el titular del cargo elegido o el partido político que lo postuló a dicho cargo. La aceptación de las órdenes de partido importa un cambio en la respuesta a dicha pregunta (al menos desde lo normativo), puesto que antes podría sostenerse que era el titular del cargo mientras que ahora lo es el partido político. Debemos aclarar que este es un análisis meramente normativo, pues las órdenes de partido o acuerdos de bancadas no eran ajenos a la dinámica política chilena.

En el mismo sentido apunta el cambio de sistema electoral, puesto que en la confección de las listas, propias del sistema proporcional D’Hondt, el rol de los

33. Biblioteca del Congreso Nacional (2016), p. 169.

34. Biblioteca del Congreso Nacional (2016), p. 271.

35. Biblioteca del Congreso Nacional (2016), p. 249.

36. Biblioteca del Congreso Nacional (2016), p. 126.

37. Biblioteca del Congreso Nacional (2016), p. 168.

38. Biblioteca del Congreso Nacional (2016), p. 271. 
partidos resulta clave, así como en la posibilidad de que resulten elegidas personas con baja votación, en la medida que representen a partidos con alta votación, aunque esta se concentre en una sola candidatura ${ }^{39}$. Reforzando la misma idea, el financiamiento público de los partidos busca evitar que sean "capturados por intereses particulares y distraerse de su rol programático" ${ }^{40}$, el que podrán ejercer entonces a través de sus parlamentarios.

Todos los cambios propuestos apuntan a fortalecer precisamente el rol de los partidos como canalizadores de la participación ciudadana ("correas transmisoras” de aspiraciones sociales), justificando por ello el financiamiento público y las exigencias de transparencia y de democracia interna ${ }^{41}$ a que son sometidos ${ }^{42}$. La discusión parlamentaria respecto de las exigencias de transparencia se ve cruzada, precisamente, por la opinión respecto del rol público o privado que deban tener los partidos políticos.

\section{Intervención estatal para asegurar el cumplimiento de su rol ¿hasta dónde?}

Se busca fortalecer así su rol público, regulando no solo la relación con sus propios afiliados, sino "con todos los interesados en las cosas políticas" ${ }^{43}$. El concebir que los partidos jueguen precisamente un rol público socialmente esperable, incide en la tensión entre regulación estatal y libertad de los partidos para tomar sus propias decisiones internas, incluso para admitir nuevos militantes. Entran en tensión también la expectativa y el derecho de los partidos a mantener su propia identidad con derechos de ciudadanos que legítimamente quieren intervenir en aspectos propios de un determinado partido. Todo ello implica un delicado equilibrio ${ }^{44}$,

39. Debemos considerar sí que el sistema de lista abierta, que se utilizará en las elecciones parlamentarias, implica un factor de moderación al mandato programático, siendo la votación individual un segundo factor a considerar en la determinación de las personas finalmente elegidas, después de la votación de la lista. A ello habría que agregar también la votación del subpacto en caso de haberlo.

40. Biblioteca del Congreso Nacional (2016), p. 43.

41. Aunque sujeta en su concreción a lo que dispongan los estatutos de los partidos, al establecer la ley la opción de elegir por votación directa a la directiva, o bien a un órgano intermedio que a su vez elija a la directiva partidaria.

42. Biblioteca del Congreso Nacional (2016) p. 45.

43. Biblioteca del Congreso Nacional (2016), p. 49.

44. Biblioteca del Congreso Nacional (2016), pp. 64, 516 y 551. 
pudiendo una fuerte intervención estatal vulnerar el pluralismo político y la libertad de asociación. El Estado financia, en este caso, a entes eminentemente privados, $-\mathrm{y}$ no podrían tener otra naturaleza en un régimen democrático- pero como contrapartida establece algunas normas mínimas de estructura dirigidas a garantizar la democracia interna y exigencias básicas de transparencia ${ }^{45}$, fundamentalmente de transparencia activa, quedando sometidos a las mismas normas que los órganos del Estado. Los estudios realizados muestran que en este aspecto los partidos, en general, tienen un nivel de cumplimiento bajo, estimándose que logran un promedio de 2,39 sobre un máximo de 7,046. Ello no podría llegar al exceso de tratarlos como órganos del Estado, lo que los desnaturalizaría. El acceso al financiamiento no debiera alterar su esencia ${ }^{47}$, ni dar pie para que el Estado controle a los partidos ${ }^{48}$, o que la actividad política sea imposible de realizar debido a trabas administrativas ${ }^{49}$.

La exigencia de cuotas de género en la integración de los órganos internos de los partidos es sin duda una intervención estatal, pues los partidos pierden algún grado de autonomía en sus decisiones internas ${ }^{50}$. Este aspecto, que no generó mayor controversia durante la tramitación parlamentaria, es una muestra de cómo el Estado busca asegurar que los partidos cumplan el rol que se les quiere asignar en el sentido de fortalecer el sistema democrático. No se aprobaron, por otro lado, cuotas de participación de jóvenes ni de pueblos originarios ${ }^{51}$, siendo estos aspectos sensibles de la representatividad de las organizaciones políticas, tal como lo son los aspectos de género. Estas últimas fueron consideradas perfectamente ajustadas a la Constitución por el Tribunal Constitucional, pues vienen a concretar la obligación constitucional de los partidos de contar con una efectiva democracia interna (artículo $19 \mathrm{~N}^{\circ} 15$ ), resguarda que estos respeten los principios básicos del ordenamiento constitucional (artículo $19 \mathrm{~N}^{\circ} 15$ ), el derecho de las personas a participar en la vida nacional con igualdad de oportunidades (artículo $1^{\circ}$ ), la prohibición de privilegios para los partidos políticos (artículo $19 \mathrm{~N}^{\circ} 15$ ) y la igualdad ante la ley de hombres y mujeres (artículo $19 \mathrm{~N}^{\circ}$ 2). Además el Tribunal Constitucional destaca

45. Biblioteca del Congreso Nacional (2016), p. 73.

46. Chile Transparente (2017), p. 16.

47. Biblioteca del Congreso Nacional (2016), p. 80.

48. Biblioteca del Congreso Nacional (2016), p. 84.

49. Biblioteca del Congreso Nacional (2016), p. 177.

50. Biblioteca del Congreso Nacional (2016), p. 329.

51. Biblioteca del Congreso Nacional (2016), p. 540. 
la coherencia con otros aspectos regulados en la propia ley ${ }^{52}$. Todas estas razones, salvo la relativa a la igualdad entre hombres y mujeres, podrían perfectamente esgrimirse para justificar cuotas basadas en la edad o el origen étnico.

Hay ciertas materias fiscalizables, aún a riesgo de la judicialización de algunas decisiones partidarias, lo que sería aceptable si se trata de cuestiones administrativas pero no si se trata de cuestiones políticas ${ }^{53}$. Sin embargo, trazar una línea divisoria entre ambas no es cuestión baladí. En definitiva, ello solo será posible caso a caso, lo que no permite dejar fuera algún grado de intervención estatal, sea a través de órganos administrativos, como el Servicio Electoral, o de órganos jurisdiccionales.

En definitiva, se opta por un sistema que implica controlar la estructura interna (su definición y su funcionamiento, incluso las elecciones internas), pero no sobre las decisiones que esta misma estructura pueda tomar, garantizando de este modo la autonomía partidaria. El foco de la regulación estatal debiese estar en la calidad de la democracia, resguardando que los partidos aporten en ese sentido. Toda limitación a la autonomía partidaria se justifica entonces en la medida en que tribute a ese objetivo.

Sin menospreciar su rol público, el legislador no ha considerado que los partidos no ostentan el monopolio de la representación de ideas e intereses en sociedades complejas como la nuestra. La experiencia comparada muestra que "es precisamente en los países donde los partidos poseen regulaciones más intensas como Portugal, Grecia y Francia, donde los partidos son desafiados y rebalsados por nuevas formas de agregación de preferencias" ${ }^{24}$. Los partidos no debiesen en consecuencia quitar espacios institucionales a nuevas formas de participación, pues surge entonces el riesgo de que estas busquen canales al margen de la institucionalidad.

\section{Algunos efectos probables y no probables de las modificaciones introducidas}

Las modificaciones introducidas provocan una desigualdad entre militantes de partidos políticos e independientes. Para inscribir un partido político, y por ende para que este partido pueda a su vez inscribir candidatos, se requieren las firmas del $0,25 \%$ de quienes hubieren votado en la última elección de Diputados, o bien de

52. Control preventivo de Proyecto de Ley, aprobado por el Congreso Nacional, que fortalece el carácter público y democrático de los partidos políticos y facilita su democratización (2016).

53. Biblioteca del Congreso Nacional (2016), pp. 113-114.

54. Biblioteca del Congreso Nacional (2016), p. 60. 
500 electores en el caso de que el mencionado porcentaje arrojare una cifra menor de firmas requeridas. Sin embargo, para inscribir una candidatura independiente, se requieren las firmas de un $0,5 \%$ de quienes hubieren votado en la última elección de Diputados. Esta última cifra era la requerida, hasta el año 2015, para inscribir partidos políticos, con lo cual se respetaba lo establecido en el inciso quinto del numeral 15 del artículo 19 de la Constitución, en el sentido de que los partidos políticos no pueden tener privilegio alguno en cuanto a la representación popular. Se producirán entonces situaciones de privilegio para los partidos políticos, quienes en definitiva podrán inscribir candidaturas contando con menor respaldo de firmas que los candidatos independientes, en once de las dieciséis regiones en que actualmente se divide el país, ${ }^{55}$ como puede apreciarse en la Tabla $\mathrm{N}^{\circ} 1$.

Tabla No 1

\begin{tabular}{|l|r|r|}
\hline Región & $\begin{array}{l}\text { Firmas necesarias para inscribir } \\
\text { un Partido Político }\end{array}$ & $\begin{array}{l}\text { Firmas necesarias para inscribir } \\
\text { una candidatura independiente }\end{array}$ \\
\hline Arica y Parinacota & 500 & 356 \\
\hline Iquique & 500 & 431 \\
\hline Antofagasta & 500 & 883 \\
\hline Atacama & 500 & 496 \\
\hline Coquimbo & 650 & 1.300 \\
\hline Valparaíso & 1.808 & 3.616 \\
\hline Metropolitana & 6.646 & 13.291 \\
\hline Libertador Bernardo O’Higgins & 917 & 1.833 \\
\hline Maule & 1.095 & 2.190 \\
\hline Nuble & 526 & 1.051 \\
\hline BíoBío & 1.611 & 3.221 \\
\hline Araucanía & 965 & 1.930 \\
\hline Los Ríos & 500 & 809 \\
\hline Los Lagos & 785 & 1.570 \\
\hline Aisén & 500 & 189 \\
\hline Magallanes y Antártica Chilena & 500 & 314 \\
\hline
\end{tabular}

Elaboración propia.

55. La estimación de basa en cálculos propios tomando como referencia la información del SERVEL respecto de la participación en las elecciones de Diputados del año 2013. 
El nivel de abstención en las elecciones se torna crítico, y es algo de recurrente discusión ${ }^{56}$, cuestión que no es objeto del presente trabajo. Una de las formas de enfrentarlo fue el cambio del sistema electoral, como se señala en el mensaje de la respectiva $l e y^{57}$, el que, como se mencionó, será ahora de carácter proporcional en virtud de la ley $\mathrm{N}^{\circ}$ 20.840. Sin embargo, los partidos políticos mantienen un rol preponderante en la definición de candidaturas, y dado el mecanismo de listas propio del sistema D’Hondt, se dificultará aún más que en un sistema binominal la elección de candidatos independientes. En definitiva, se deja de lado el criticado sistema binominal, mas no se apunta a un sistema que dé cuenta de los fenómenos actuales en materia de participación política y electoral. El sistema que se utilizará a partir de ahora, considerando tanto el sistema electoral como el rol de los partidos políticos, es prácticamente idéntico al que se utilizaba antes de la dictadura en Chile, es decir, un sistema propio de la primera mitad del siglo XX, y adecuado por tanto a su época.

\section{Gráfico No 1}

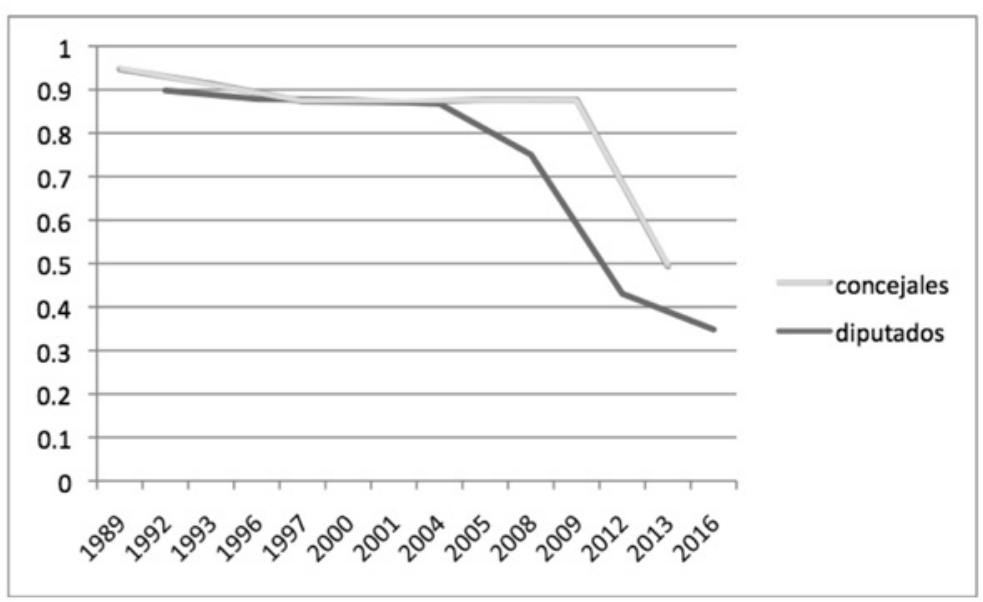

Elaboración propia.

Si comparamos el nivel de participación en elecciones de Diputados (con sistema binominal y simultaneidad con la elección presidencial salvo en 1997 y 2001) con el nivel de participación en las elecciones de Concejales (con sistema proporcional D'Hondt que se utilizará a partir de ahora para en las elecciones parlamentarias)

56. Makarov (2017), p. 8.

57. Biblioteca del Congreso Nacional (2015), p. 3. 
veremos que no hay mayores diferencias (ver gráfico $\mathrm{N}^{\circ} 1$ ). En consecuencia, podemos afirmar que la intención de mejorar el nivel de participación al introducir el sistema proporcional en las elecciones parlamentarias no tiene sustento empírico, y por ende no es esperable que produzca efectivamente una mejora en estos índices.

Cabe señalar que al hacer esta comparación no se debe olvidar que la naturaleza de lo que se decide en elecciones generales y locales es diversa, y que los factores que inciden en la decisión de los ciudadanos de votar no son necesariamente los mismos; sin embargo, algún indicio entregan respecto de la valoración del sistema político, en el cual los partidos políticos ocupan un lugar central. Debe también considerarse que en la última elección municipal, el año 2016, en la que se registra la menor tasa de participación, existieron problemas con el padrón electoral ${ }^{58}$, sin los cuales la tasa de participación podría haber sido levemente superior. Podemos concluir entonces que el hecho de tratarse de elecciones generales o locales, o el uso de un sistema proporcional o binominal no tienen mayor incidencia en los índices de participación electoral, observándose una baja sostenida en la misma, llegando a ser, en la última elección general (el año 2013), una de las más bajas de los países de la $\mathrm{OCDE}^{59}$. Por ello no es dable pensar que la participación vaya a aumentar dramáticamente en las próximas elecciones parlamentarias, aunque podría haber un leve aumento comparado con la última elección de Concejales, dados los referidos problemas del padrón electoral en la última elección municipal y la circunstancia de que desde el año 2009 se aprecie una mejor tasa de participación si se la compara con la elección municipal del año inmediatamente anterior. Aún así, y tal como ocurrió, no era esperable que supere el 49,35\% registrado en las elecciones parlamentarias y presidenciales de 2013.

\section{Aspectos no considerados por el legislador}

Existe una evidente relación entre sistemas electorales y sistemas de partidos políticos. Dieter Nohlen dedica un capítulo completo al problema en su clásica obra Sistemas Electorales y Partidos Políticos ${ }^{60}$. Revisando los últimos años de evolución del sistema político chileno, se podría pensar que el sistema electoral binominal

58. GÓMEz (2016).

59. OECD (2017), p. 6.

60. NohLEN (1995), p. 34. 
redujo la fragmentación del sistema de partidos ${ }^{61}$, ya que "los partidos pequeños, sin posibilidad de ganar elecciones, tienden a desaparecer, concentrando así la competencia política" ${ }^{62}$. Sin embargo, también hay quienes señalan que ello no es efectivo, pero lo que ha hecho, más que disminuir el número de partidos, ha sido "frenar la aparición de un tercer pacto con peso real en las cámaras" ${ }^{63}$. Sin pretender entrar en ese debate en el presente trabajo, vale la pena llamar la atención sobre lo poco adecuado que resulta entonces haber realizado cambios al sistema electoral sin mirar a fondo el sistema de partidos imperante.

Aún a riesgo de aventurar un juicio prematuro, el comportamiento de los partidos al configurar las listas parlamentarias para la elección de noviembre del presente año responde más a una lógica propia del sistema binominal que del proporcional, que se utilizará por vez primera desde el retorno de la democracia para elegir Diputados y Senadores. Ello refleja el problema que advertimos, en el sentido de modificar solo una de las variables que debieron haberse considerado para producir un cambio en el sistema político.

No se consideró en el debate parlamentario la relación entre sistema de gobierno y sistema electoral, existiendo quienes sostienen la incompatibilidad del sistema electoral proporcional con el régimen presidencialista, el que no se ha modificado, llegando al extremo de señalar que este sistema electoral sería responsable del quiebre institucional que condujo a la dictadura en $1973 .{ }^{64}$ Aun cuando esta tesis pueda ser perfectamente debatida, y el autor de este trabajo no la comparte, la mera existencia de dicha discrepancia deja en evidencia la necesidad de abordar también esta variable al revisar las modificaciones a la regulación legal de los Partidos Políticos.

Se deja fuera del análisis la estructura misma del Estado. Hay alguna discusión sobre el rol y existencia de partidos regionales, sin relacionar ello con fenómenos o modificaciones constitucionales recientes ${ }^{65}$ relativas al problema de la regionalización y descentralización ${ }^{66}$. Se advierte, por ejemplo, el riesgo de "fragmentación

61. VON BAer (2007), p. 118.

62. LÓPEZ (2014), p. 46.

63. LÓPEz (2014), p. 61.

64. LÓPEZ (2014), p. 21.

65. Ley de reforma constitucional 20.990, que si bien es posterior a la reforma de la ley de partidos políticos, el tema que aborda, la elección de los Intendentes (denominados ahora Gobernadores Regionales) es de larga data en nuestro país.

66. Biblioteca del Congreso Nacional (2016), pp. 555 y 557. 
del sistema de partidos" ${ }^{67}$, con una clara mirada parcial y centralista del problema. No se advierte el que puedan haber partidos diversos (no solo de carácter regional), intentando homologar las normas para todos los partidos ${ }^{68}$, cuestión que en definitiva llevó a regular la estructura interna en términos amplios y vagos, para dar cabida dentro del marco legal a la actual estructura de todos los partidos tradicionales representados actualmente en el Congreso Nacional ${ }^{69}$.

El no considerar estos elementos responde a una suerte de voluntarismo, como si solo con modificaciones legales se pudiese cambiar la realidad de las cosas, creyendo queexiste una estricta separación entre ley y política, lo que muchos ponen en duda ${ }^{70}$. No se trata de menospreciar el rol de la legislación, especialmente la electoral y de partidos político, en modelar el sistema político. La existencia de un sistema bipartidista o multipartidista podrá verse influido por la legislación, pero esta no puede pretender desconocer la conformación de la sociedad política; no es rol del Estado determinar el número de partidos que puedan existir, pero a través de normas jurídicas puede incentivar uno u otro sistema. Se olvida que los partidos políticos surgen con anterioridad a su reconocimiento legal y constitucional ${ }^{71}$. Es además una nueva muestra de cómo se abordan los problemas institucionales en forma aislada, descuidando la necesaria coherencia constitucional, cuestión que va mermando la fundamentalidad del texto constitucional.

Existen barreras legales de representación, pero no en el sentido que normalmente tienen en derecho comparado ${ }^{72}$. En nuestro medio un partido político que no logre un determinado umbral de votación (cinco por ciento) mantendrá la representación parlamentaria, siendo la regla usual que la pierda, pero perderá su carácter de partido político legal. Ello no es nuevo, pero sí es novedoso en el contexto de un sistema proporcional y de un mayor número de parlamentarios, con lo que se darán casos de parlamentarios electos que por disposición legal perderán el respaldo partidario con el que postularon al Congreso. Ello implica subestimar el rol de los partidos políticos. Supone que el parlamentario no requiere de soporte político para desarrollar adecuadamente su función, empujándolo de algún modo a

67. Biblioteca del Congreso Nacional (2016), p. 61.

68. Biblioteca del Congreso Nacional (2016), p. 462.

69. Biblioteca del Congreso Nacional (2016), p. 520.

70. Corrias (2016), p. 16.

71. Biblioteca del Congreso Nacional (2016), p. 59.

72. LÓPEz (2014), p. 18. 
transformarse en un parlamentario independiente, o a buscar dicho apoyo en otra tienda política, produciendo así una distorsión en la representación parlamentaria, cuestión que el cambio de sistema buscaba evitar ${ }^{73}$.

Este mecanismo responde a la idea de no tener barreras de entrada muy exigentes, vale decir, resulta fácil constituir partidos políticos, generando el riesgo del multipartidismo ${ }^{74}$, pero contar con barreras de salida ${ }^{75}$, es decir, evitar la existencia de partidos políticos que no logren un mínimo de respaldo ciudadano en las elecciones, cuestión que en opinión de Fuentes, facilitaría la creación de partidos políticos pero limitaría la competencia de los $\operatorname{mismos}^{76}$, especialmente para los que quieran entrar en el sistema político ${ }^{77}$. Esto será algo novedoso en un contexto de sistema electoral proporcional, pues no existía bajo la vigencia de la Constitución de $1925^{78}$.

Dada la importancia del sistema electoral para el funcionamiento del régimen democrático, llama la atención que este sea regulado íntegramente en la ley, sin un marco constitucional básico. Poco tiempo después de entrar en vigencia la actual Constitución se encomienda a la Comisión de Estudio de las Leyes Orgánicas Constitucionales (Comisión Fernández) “proponer a la Junta de Gobierno un proyecto de sistema electoral aplicable a nuestro país"79. Ello fue el origen del artículo 109 bis de la Ley No 18.700 , Orgánica Constitucional de Votaciones Populares y Escrutinios, que estableció el sistema binominal y cuya modificación establece ahora el sistema proporcional D'Hondt. La Constitución de 1925, si bien no establecía un sistema electoral en particular, sí señalaba que este debía ser de carácter proporcional ${ }^{80}$. La actual Constitución, en su texto original, no hacía mención alguna al sistema electoral, sin embargo, estableció que cada región debía elegir dos Senadores ${ }^{81}$, lo

73. Biblioteca del Congreso Nacional (2015), p. 119.

74. Biblioteca del Congreso Nacional (2016), p. 418.

75. Biblioteca del Congreso Nacional (2016), pp. 232, 314 y 344.

76. Biblioteca del Congreso Nacional (2016), p. 53.

77. Biblioteca del Congreso Nacional (2016), p. 267.

78. LÓPEZ (2014), p. 20.

79. LÓPEZ (2014), p. 24.

80. El artículo 25 establecía: “En las elecciones de Diputados y Senadores se empleará un procedimiento que dé por resultado en la práctica una efectiva proporcionalidad en la representación de las opiniones y de los partidos políticos”. Valencia (1986) p. 219.

81. El artículo 45 inciso $1^{\circ}$ establecía: "El Senado se integrará con miembros elegidos en votación directa por cada una de las trece regiones del país. A cada región corresponderá elegir 
que podría ser interpretado como la base constitucional del sistema binominal, cuestión que no compartimos ${ }^{82}$, puesto que bien se podría haber implementado un sistema mayoritario perfectamente coherente con el texto constitucional. Respecto de los Diputados, solo se establecía que serían ciento veinte ${ }^{83}$.

La Ley 20.050, el año 2005, eliminó la referencia a los dos Senadores por región, y estableció que las modificaciones "que digan relación con el número de senadores, las circunscripciones existentes y el sistema electoral vigente, requerirán del voto conforme de las tres quintas partes de los diputados y senadores en ejercicio" ${ }^{84}$. Con ello, lejos de sacar el sistema binominal de la Constitución, como se pretendía, se le introdujo en la misma, al establecer una curiosa ley que debe ser aprobada con quórum de reforma constitucional ${ }^{85}$. Con posterioridad se eliminó la referencia al número de diputados del texto constitucional, el año 2014, posibilitando así la reforma al sistema proporcional cuyo diseño implicaba aumentar el número de Diputados.

\section{Conclusiones}

El Estado toma la decisión de costear la actividad política, mediante el financiamiento de campañas electorales y del funcionamiento permanente de los partidos políticos, asumiendo que ambas instituciones son claves para la existencia de una democracia robusta. Se reconoce así el carácter público y democrático de los partidos políticos, dado que éstos “articulan las demandas de la ciudadanía, sus intereses y valores, por ello, los partidos son instancias fundamentales para canalizar los conflictos o disensos que naturalmente se dan en las sociedades democráticas" ${ }^{86}$. Se les considera fundamentales para el sistema democrático, un instrumento de participación ciudadana, de integración de ideas y proyectos sociales y actores centrales en el

dos senadores, en la forma que determine la ley orgánica constitucional respectiva”. VALENCIA (1986) p. 374.

82. BECA (2002), p. 63.

83. El artículo 43 inciso $1^{\circ}$ establecía: "La Cámara de Diputados está integrada por 120 miembros elegidos en votación directa por los distritos electorales que establezca la ley orgánica constitucional respectiva". VALENCIA (1986), p. 374.

84. Disposición cuadragésima segunda (actualmente decimotercera) transitoria inciso segundo de la Constitución. Ley 20.050, de 2005.

85. BECA (2010), p. 64

86. Biblioteca del Congreso Nacional (2016), p. 5. 
debate de políticas públicas ${ }^{87}$; y ello es innegable, pero responde a una lógica que se ve desafiada por la realidad política. Hay actualmente otros cauces de participación democrática que no se han tomado en cuenta. Como gráficamente se señaló durante la tramitación parlamentaria: "el envase sigue siendo el mismo, pero el contenido ha cambiado de manera radical" 88 .

El mensaje del proyecto de ley que analizamos caracteriza el sistema de partidos en Chile como "muy cerrado, que no se ha podido adaptar a los cambios y al proceso de modernización que ha experimentado la sociedad". Compartiendo el diagnóstico, disentimos en la solución. Se ha perfeccionado un sistema, pero no se ha mudado el paradigma que lo inspira, es decir, hay más (y mejor) de lo mismo, pero sigue siendo lo mismo. Fundamos esta opinión en que se mantiene una estructura rígida de los partidos, diseñada para partidos de masa (con un alto de número de militantes activos), así como la visión de los partidos como los únicos entes capaces de canalizar la representación política y la transmisión de inquietudes desde la ciudadanía hacia los órganos del Estado.

\section{Referencias bibliográficas}

BECA, Juan (2002): "Sistema Electoral y Reformas a la Constitución". En Revista de Derecho Universidad de Concepción, Año LXX, No 212 vol. I, pp. 63-70.

Biblioteca del Congreso Nacional (2015) “Historia de la Ley 20.840”. Disponible en http://www.bcn.cl/historiadelaley/fileadmin/file_ley/3997/HLD_3997_3 7a6259cc0c1dae299a7866489dff0bd.pdf. [Fecha de consulta: 20 de septiembre de 2017].

Biblioteca del Congreso Nacional (2016) "Historia de la Ley 20.915”. Disponible en http://www.bcn.cl/historiadelaley/fileadmin/file_ley/4920/HLD_4920_3 7a6259cc0c1dae299a7866489dff0bd.pdf. [Fecha de consulta: 20 de septiembre de 2017].

Chile Transparente (2017) "Índice de Transparencia en Partidos Políticos. Informe 2017”. Disponible en https://www.partidostransparentes.cl/wp-content/ uploads/2017/04/informe-final-itpp-2017.pdf. [Fecha de consulta: 22 de noviembre de 2017].

87. Biblioteca del Congreso Nacional (2016), pp. 4-5.

88. Biblioteca del Congreso Nacional (2016), p. 265. 
CONSEJO ASESOR PRESIDENCIAL CONTRA LOS CONFLICTOS DE INTERÉS EL TRÁFICO DE INFLUENCIAS Y LA CORRUPCIÓN “Informe Final”. Disponible en http://www.minsegpres.gob. cl/wp-content/uploads/2017/04/Informe-del-Consejo-Asesor-PresidencialContra-los-Conflictos-de-Intereses-el-trafico-de-Influencias-la-Corrupcion. pdf. [Fecha de consulta: 20 de septiembre de 2017].

Corrias, Luigi (2016): "Populism in a Constitutional Key: Constituent Power, Popular Sovereignty and Constitutional Identity”. En European Constitutional Law Review, Vol. $12 \mathrm{~N}^{\mathrm{o}}$ 1, Junio de 2016, pp. 6-26.

De Cea, Maite y Fuentes, Claudio (2016): “Vendiendo soluciones. Campañas tradicionales y profesionalizadas en Chile”. En Revista Internacional de Sociología, Vol. 74 N 3, 2016. Disponible en http://revintsociologia.revistas. csic.es/index.php/revintsociologia/article/view/655/770\#resumen. [Fecha de consulta: 22 de noviembre de 2017].

Gómez, Uziel. "La Historia Oculta del Padrón Gate: El Servel advirtió el problema al Registro Civil durante dos años”. Disponible en: http://ellibero.cl/actualidad/ la-historia-oculta-del-padrongate-el-servel-advirtio-el-problema-al-registrocivil-durante-dos-anos/. [Fecha de consulta: 20 de septiembre de 2017].

LóPEz, Orlando. "Sistema binominal orígenes y objetivos: efectos y críticas del sistema, necesidad de una reforma”. Disponible en http://repositorio.uahurtado.cl/ handle/11242/7437 . [Fecha de consulta: 20 de septiembre de 2017].

LunA, Juan Pablo (2008): "Partidos Politicos y Sociedad en Chile. Trayectoria Histórica y Mutaciones Recientes”. En FontaIne, Arturo; Larroulet, Cristián; Navarrete, Jorge y Walker, Ignacio. Reforma de los Partidos Políticos en Chile (Santiago de Chile, PNUD, CEP, Libertad y Desarrollo, Proyectamérica y CIEPLAN), pp. 75-125.

MaKarov, Denis (2017): Classrooms for Democracy (Dayton, Kettering Foundation Press).

Nohlen, Dieter (1995): Sistemas Electorales y Partidos Políticos (Ciudad de México, Editorial Fondo de Cultura Económica).

OECD. "Chile. Scan Report on the Citizen Participation in the Constitutional Process 2017”. Disponible en: https://www.oecd.org/gov/public-governance-reviewchile-2017.pdf. [Fecha de consulta: 18 de agosto de 2017].

Programa de Naciones Unidas para el Desarrollo (2014): Auditoría de la Democracia. Más y mejor democracia para un Chile inclusivo. (Santiago de Chile, Gráfica LOM).

Valencia, Luis (1986): Anales de la República (Santiago de Chile, Editorial Andrés Bello).

Von Baer, Ena (2007): “Sistema Binominal: Consensos y Disensos”. En Fontaine, 
Arturo; Larroulet, Cristián; Navarrete, Jorge y Walker, Ignacio. Reforma del Sistema Electoral Chileno (Santiago de Chile, Programa de Naciones Unidas para el Desarrollo), pp. 177-206.

\section{Jurisprudencia citada}

Control preventivo de Proyecto de Ley, aprobado por el Congreso Nacional, que fortalece el carácter público y democrático de los partidos políticos y facilita su democratización (2016): Tribunal Constitucional Rol 2980-16-CPR. 24 de marzo de 2016. Disponible en http://www.tribunalconstitucional.cl/ sentencias/busqueda-basica [Fecha de consulta: 20 de septiembre de 2017]. 